\title{
Controlling tick borne diseases through domestic animal management: a theoretical approach
}

\author{
R Porter R Norman L Gilbert
}

The original publication is available at www.springerlink.com. Published in Theoretical Ecology, available online 20 May 2010. http://www.springerlink.com/content/7487387811473886/

\begin{abstract}
Vector-borne diseases are of global importance to human and animal health. Empirical trials of effective methods to control vectors and their pathogens can be difficult for practical, financial and ethical reasons. Here, therefore, we use a mathematical model to predict the effectiveness of a vector-borne disease control method. As a case study we use the tick-louping ill virus system, where sheep are treated with acaricide in an attempt to control ticks and disease in red grouse, an economically important game bird. We ran the model under different scenarios of sheep flock sizes, alternative host (deer) densities, acaricide efficacies and tick burdens. The model predicted that, with very low deer densities, using sheep as tick mops can reduce the tick population and virus prevalence. However, treatment is ineffective above a certain threshold deer density, dependent on the comparative tick burden on sheep and deer. The model also predicted that high efficacy levels of acaricide must be maintained for effective tick control. This study suggests that benignly managing one host species to protect another host species from a vector and pathogen can be effective under certain conditions. It also highlights the importance of understanding the ecological complexity of a system, in order to target control methods only under certain circumstances for maximum effectiveness.
\end{abstract}

R Porter R Norman,

Department of Computing Science and Mathematics, University of Stirling, Stirling, FK9 4LA, UK.

Tel.: +44-1786-467449 rbp@cs.stir.ac.uk

L Gilbert,

Macaulay Land Use Research Institute, Cragiebuckler, Aberdeen, AB31 8QH

\section{Introduction}

Vector-borne diseases are of global importance to human health, animal welfare, economics and biodiversity. In Europe ticks are the most important vector of zoonotic pathogens, which include Borrelia burgdorferi the agent of Lyme borreliosis and the tick borne encephalitis (TBE) complex of viruses. The abundance and distribution of Ixodes ricinus ticks in the British Isles are increasing (Scharlemann et al., 2008; Pietzsch et al., 2005; Kirby et al., 2004). Theoretically, reducing vector populations will mitigate disease incidence. Here we use mathematical models to explore the effectiveness of tick control strategies in reducing ticks and disease prevalence and increasing the population of susceptible species. We use the louping-ill virus (LIV) system as a particularly interesting case study because land managers are currently attempting to kill ticks on one species in the hope of increasing the population of another species. However, the theory could be applied to any vector-borne pathogen system.

LIV causes a tick borne disease of great importance to livestock farmers and game keepers as it causes symptomatic infection in both sheep (Ovis aries) and red grouse (Lagopus lagopus scoticus). LIV infection can lead to severe illness and death in both animals, with up to $80 \%$ of experimentally infected red grouse dying from the disease (Reid, 1975). Between 1985 and 2003 a rise in the tick burdens was found on red grouse chicks on 13 sites in Scotland (Kirby et al., 2004). This suggests that red grouse chicks may be at an increasing risk of contracting LIV. 
The Biology of Louping Ill Virus LIV is transmitted by the three stage sheep tick which feeds on a variety of hosts. Each stage (larva, nymph, adult) requires a blood meal from a vertebrate host before moulting into the next life stage. Following reproduction the adults die. It is important to note that adult $I$. ricinus ticks rarely feed on red grouse so grouse alone cannot sustain the tick population.

Ticks acquire the virus after feeding from an infected host. There is no transovarial transmission so newly hatched larvae do not carry virus (Gaunt, 1997). Once a tick is infected it can pass on the infection to a host when it takes the next feed during the next life stage. In addition red grouse chicks feed on various invertebrates during the first three weeks after hatching and can acquire the infection after ingesting an infected tick (Gilbert et al., 2004).

Control Strategies of Louping Ill Virus Sheep can be vaccinated against the virus and treated with acaricide to kill ticks which try to attach. This, when conducted properly, can reduce LIV prevalence in sheep farms (Laurenson et al., 2007). Red grouse however cannot easily be treated in a cost effective manner, although tick burdens have been successfully reduced experimentally on small numbers of grouse using acaricidal wing tags (Laurenson et al., 1997) and treating hens with permethrin coated leg bands (Mougeot et al., 2008). This is unlikely to be practicable on a commercial basis.

Mountain hares (Lepus timidus) have been shown experimentally to allow LIV transmission nonviraemically between co-feeding ticks (Jones et al., 1997). As a result some grouse managers are conducting extensive culls of mountain hares in an effort to reduce LIV prevalence in red grouse. However, models predict that culling mountain hares can reduce LIV in red grouse only in the absence of other tick hosts, such as red deer (Gilbert et al., 2001). Therefore, red deer (Cervus elaphus) are also culled in some areas due to their importance as tick reproduction hosts (Gray, 1998), even though they do not transmit LIV.

A more benign method of controlling LIV in red grouse could be using sheep as 'tick mops'. In sheep tick mop experiments sheep are actively being used to try and 'mop up' the tick population by killing those ticks that try to attach. The sheep are treated every six weeks with acaricide and put out on the moor in the hope that they will reduce the tick population and thus reduce LIV in the grouse population. The sheep are also vaccinated against LIV. Variable success in reducing LIV prevalence in sheep has been recorded in Northern England (Laurenson et al., 2007). However it is not known how effective sheep mops are at reducing LIV in red grouse, or in areas with alternative tick hosts, e.g. mountain hares and red deer. The Game and Wildlife Conservation Trust (GWCT) is currently conducting trials to test the effects of sheep tick mops on the tick burden of red grouse chicks in the presence of alternative tick hosts in Scotland.

A theoretical approach It is important to understand the factors which affect tick population dynamics to understand how ticks and tick borne diseases might be controlled. This is especially true when empirical trials of tick control methods are made difficult through practical and ethical constraints. Mathematics has a well established history of use in describing the dynamics of tick borne diseases (Cooksey et al., 1990; O'Callaghan et al., 1998; Rosa and Pugliese, 2007; Hartemink et al., 2008). Our aim is to investigate theoretically the effectiveness of controlling a vector-borne disease in one species by reducing the vector population through the management of a second species. The management of one species to control disease in another species is an interesting but not a novel concept. Other applications of this theory include culling badgers (Meles meles) to control bovine tuberculosis in cattle (Donnelly et al. (2006), Woodroffe et al. (2006)) and culling bison (Bison bison) to control brucellosis in cattle (USDA-APHIS, 2009).

This study involves a more benign treatment strategy, acaricide use as opposed to culling, and is also unusual in that livestock are being managed to control a wildlife disease. Our case study of the LIV system aims to test the effectiveness of sheep tick mops at (i) reducing I. ricinus tick populations, (ii) reducing LIV prevalence in red grouse and (iii) increasing the red grouse population. The LIV system is particularly interesting because a large number of hosts interact; grouse, sheep, deer and mountain hares all contribute to the persistence of the pathogen.

An SIR type mathematical model of coupled differential equations for grouse and ticks is used to answer the following questions; 1) How does the addition of a treated sheep flock affect ticks, LIV and grouse compared to grouse moors with no sheep at all? 2) How do alternative hosts, such as deer, impact on the effectiveness of treated sheep? 3) What is the impact of different flock sizes on the effectiveness of 
Table 1: The model parameters. Values are per month unless otherwise stated.

\begin{tabular}{lll}
\hline Parameter & Value & Explanation and Justification \\
\hline$a_{g}$ & 0.167 & Natural birth rate of grouse. Grouse have four chicks per pair on average Reid (1975) \\
\hline$s_{g}$ & 0.0003 & Density dependence constraint on grouse. Estimated from model \\
\hline$b_{g}$ & 0.087 & Natural death rate of grouse. (Reid, 1975) \\
\hline$\alpha$ & 5 & Disease induced death rate of grouse, approx. 6 days after infection (Reid, 1975) \\
\hline$\gamma$ & 1.25 & Recovery rate of infected grouse. Calc. from $\alpha$ as $80 \%$ infected grouse die (Reid, 1975) \\
\hline$a_{t}$ & 83.33 & Natural birth rate of ticks. Assumed adult females hatch 1000 eggs a year (Gilbert et al., 2001) \\
\hline$s_{t}$ & 0.000002 & Density dependence constraint on ticks. Estimated from model \\
\hline$b_{t}$ & 0.083 & Natural death rate of ticks. Ticks estimated to live for 3 years (Gilbert et al., 2001) \\
\hline$P$ & 0.109 & Proportion of infected ticks that infect a grouse when ingested. (Gilbert et al., 2004) \\
\hline$\beta_{1}$ & 0.00002 & Rate at which a tick bites and infects a grouse. Estimated from model \\
\hline$\beta_{2}$ & $9.75 \beta_{1}$ & Rate at which a tick bites an infected grouse and becomes infected. (Gilbert et al., 2001) \\
\hline$\beta_{3}$ & $7 \beta_{1}$ & Rate at which ticks are ingested by a grouse. See $\S 2.3$ \\
\hline$\beta_{5}$ & $8.82 \beta_{1}$ & Rate at which an adult female tick bites a deer and reproduces. (Gilbert et al., 2001) \\
\hline$\beta_{6}$ & see $\S 2.3$ & Rate at which an adult female tick bites a sheep and reproduces. See $\S 2.3$. \\
\hline$\beta_{7}$ & see $\S 2.3$ & Rate at which a larvae or nymph bites a sheep. See $\S 2.3$. \\
\hline$d$ & varied & Efficacy level of the acaricide. Varied for comparisons. \\
\hline \hline
\end{tabular}

treated sheep? 4) How does the efficacy of the acaricide impact on the effectiveness of treated sheep? Our ultimate goal is to provide a critical flock size and acaricide efficacy level and describe how this is affected by the presence of other host species.

\section{Methods}

\subsection{The sheep model}

The model is an extension of that developed in Gilbert et al. (2001). The grouse population, $G$, is split in to three classes: susceptible, $G_{s}$, infected, $G_{i}$ and immune, $G_{z}$. The tick population, $T$, is split in to two classes: susceptible, $T_{s}$ and infected, $T_{i}$. (NB. The different tick stages are combined here and any differences are incorporated into the parameter values.) Deer, $D$, are included as tick reproduction hosts.

As a result of recent work (Porter et al, unpublished) the model has been extended to include ingestion of ticks as an additional route of infection in red grouse. Young grouse eat invertebrates, including ticks, for the first three weeks after hatching. In Gilbert et al. (2004) it was highlighted that a high proportion of chicks may be infected with LIV as a result of ingesting infected ticks. The model has been adapted to take this in to account. In the model below the terms that are underlined describe these additional ingestion terms.

Sheep can be vaccinated against LIV and treated with acaricide. Consequently sheep are no longer considered important tick hosts and have previously been ignored in models concerning the dynamics of LIV (Gilbert et al., 2001; Laurenson et al., 2003). However, in the case of sheep being used as tick mops they should be included because they play an active role in tick removal. Sheep feed all 3 stages of the tick: larvae, nymphs and adults. Only the adult ticks can reproduce to continue the population cycle. In the model we assume all stages of tick attaching to the sheep may be killed by the acaricide. The effect of killing an adult female tick is greater than that of killing a larva or nymph because it will prevent her from potentially laying 1000 eggs. The two terms in the model that relate to the tick biting rate on sheep are $\beta_{6}$ for adult females and $\beta_{7}$ for larvae and nymphs. These reflect the proportion of the different tick life stages that make up the total tick burden on sheep. The efficacy of the acaricide was also investigated and is given by $d, 0 \leq d \leq 1$, where $d$ represents the proportion of ticks attempting to attach to sheep killed by the acaricide. These terms describing the role of acaricide treated sheep are highlighted in the boxes in the model below.

In this model mountain hares and the role they play in non-viraemic transmission (NVT) are not being considered. Many places where there are concerns about ticks and LIV that are using sheep as 'tick mops' have few hares as a result of culling in an attempt to control ticks. The inclusion of NVT also brings an added complexity to the model. Consequently the terms for hares (compared to Gilbert et al. (2001)) have 


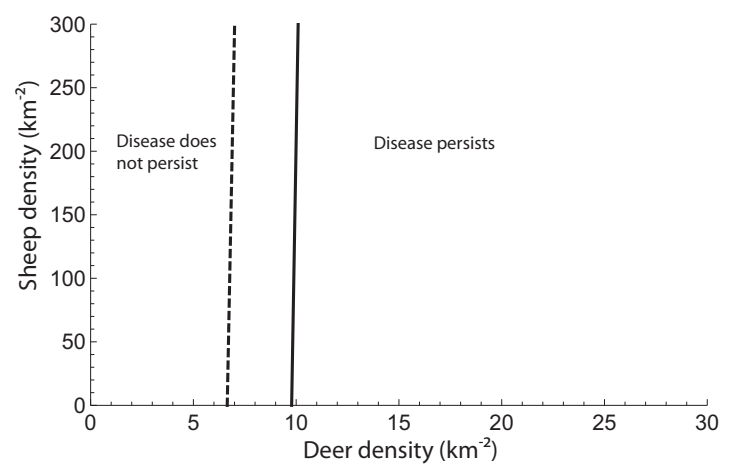

(a) low sheep tick burden

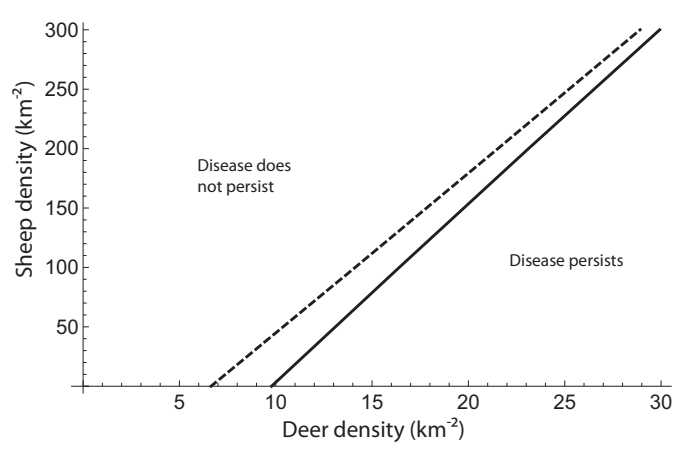

(b) high sheep tick burden

Figure 1: The areas of disease persistence for different sheep and deer densities, with sheep having a) a low tick burden or b) a high tick burden. See The Sheep Parameters section below for an explanation of low and high tick burdens. The solid line represents the line given by solving $R_{0}=1$. The dashed line represents the disease persistence threshold line from model simulations. The area in between the lines denotes where the model predicts the disease persists but $R_{0}<1$. Sheep are treated with acaricide of $100 \%$ efficacy.

been dropped and the findings of this study will apply only to hare free environments. (NVT has been discussed in detail in Norman et al. (2004)).

$$
\begin{aligned}
\frac{d G_{s}}{d t}= & \left(a_{g}-s_{g} G\right) G-b_{g} G_{s}-\beta_{1} T_{i} G_{s}-\underline{P \beta_{3} T_{i} G_{s}} \\
\frac{d G_{i}}{d t}= & \underline{P \beta_{3} T_{i} G_{s}}+\beta_{1} T_{i} G_{s}-\Gamma G_{i} \\
\frac{d G_{z}}{d t}= & \gamma G_{i}-b_{g} G_{z} \\
\frac{d T_{s}}{d t}= & \left(a_{t}-s_{t} T\right) T\left(\beta_{5} D+\beta_{6}(1-d) S\right)-b_{t} T_{s}-\beta_{2} T_{s} G_{i} \\
& -\underline{\beta_{3} T_{s} G}-\left(\beta_{5} D+\beta_{6} S+d \beta_{7} S\right) T_{s} \\
\frac{d T_{i}}{d t}= & \beta_{2} T_{s} G_{i}-\underline{\beta_{3} T_{i} G}-b_{t} T_{i}-\left(\beta_{5} D+\beta_{6} S+d \beta_{7} S\right) T_{i}
\end{aligned}
$$

where $\Gamma=\alpha+b_{g}+\gamma$.

\subsection{The Reproductive Value, $R_{0}$}

The reproductive value of a virus is a useful aid in determining the factors that will allow the virus to persist or cause it to die out. $R_{0}$ is defined as the number of new disease cases caused by adding one infected individual to a totally susceptible population. If the value of $R_{0}$ is less than one the disease will not persist, for $R_{0}$ greater than one the disease will persist. $R_{0}$ can be found by analysing the equations using the methods of Norman et al. (2004). For the sheep model $R_{0}$ is given by:

$$
R_{0}=\frac{\beta_{2}\left(\beta_{1}+P \beta_{3}\right) K_{g} K_{t}}{\Gamma\left(\beta_{5} D+\beta_{6} S+d \beta_{7} S+\beta_{3} K_{g}+b_{t}\right)}
$$

where $K_{g}$ and $K_{t}$ denote the carrying capacity of grouse and ticks respectively and are given by

$$
K_{g}=\frac{a_{g}-b_{g}}{s_{g}}
$$




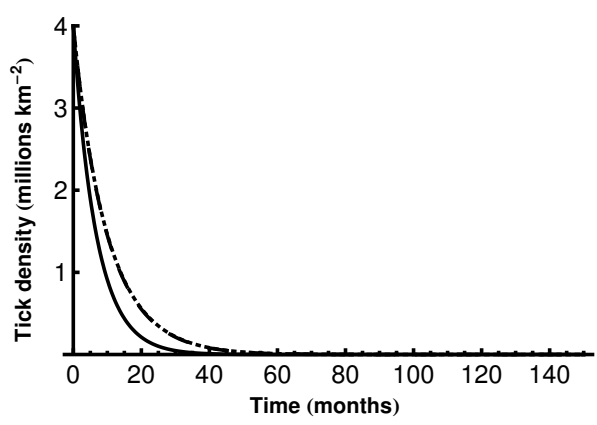

(a) Predicted tick densities

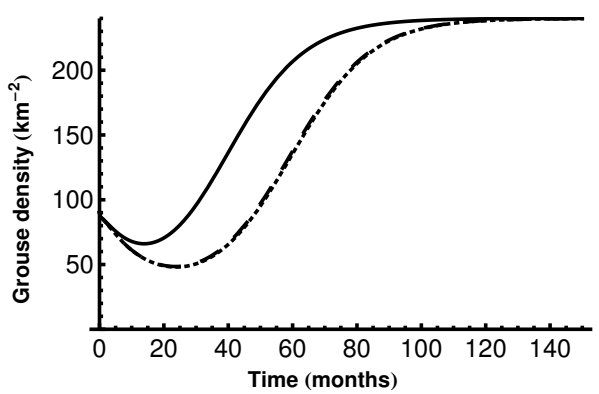

(c) Predicted grouse densities

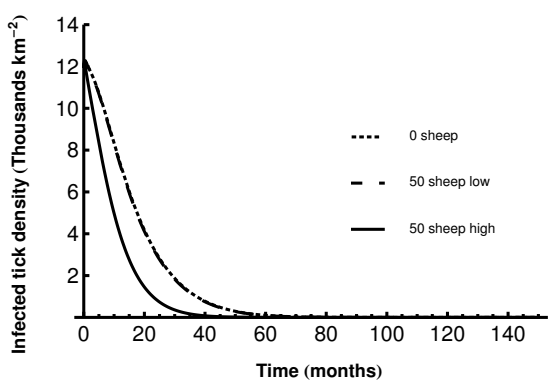

(b) Predicted infected tick densities

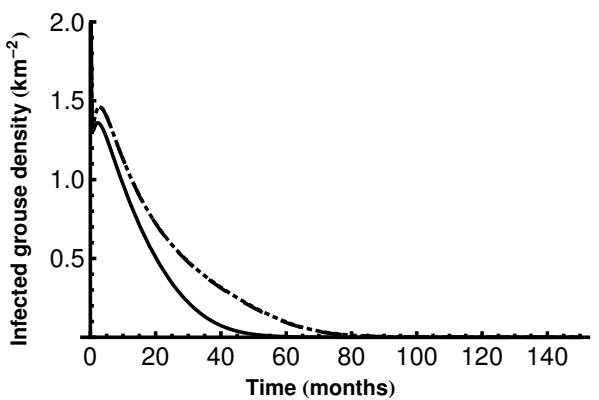

(d) Predicted infected grouse densities

Figure 2: The predicted effect of adding sheep treated with acaricide of $100 \%$ efficacy on a)tick, b)infected tick, c)grouse and d)infected grouse densities over time. No other hosts were present. The dotted line (mostly hidden by the dashed line) represents no sheep. The dashed line 50 sheep per $\mathrm{km}^{2}$ with low tick burden. The solid line represents 50 sheep per $\mathrm{km}^{2}$ with high tick burden.

and

$$
K_{t}=\frac{\left(a_{t}-1\right)\left(\beta_{5} D+\beta_{6}(1-d) S\right)-b_{t}-\beta_{3} K_{g}-d\left(\beta_{6}+\beta_{7}\right) S}{s_{t}\left(\beta_{5} D+\beta_{6}(1-d) S\right)} .
$$

However, due to the interesting dynamics that the ingestion of ticks by grouse chicks adds to this system using $R_{0}$ in this form underestimates the potential for disease spread. The ingestion of ticks included as a route of infection and a mechanism for tick removal causes a feedback loop in the system once sheep and/or deer densities are sufficient to allow LIV transmission. When the virus is able to establish it reduces the grouse population, this then allows the tick population to increase (as there are fewer ticks being ingested). The increased tick population increases the potential for disease transmission which further reduces the grouse population and so on.

Fig. 1 shows the line $R_{0}=1$, calculated from the equations given above and also the disease persistence threshold (DPT) line, which is the estimated threshold for disease persistence using model simulations to detect when the virus does and does not persist. It can be seen in Fig. 1 that the $R_{0}=1$ line is to the right hand side of the DPT line, giving an area between the two lines where the disease is persisting even though $R_{0}<1$. This is because the estimate of $R_{0}$ from the equation is unable to account for the feedback within the system. In our discussion we refer to the DPT line rather than $R_{0}=1$, as this is the threshold of disease persistence given by the model simulations.

\subsection{Parameter Estimation}

Many parameters values have been published previously and their estimation is more fully explained in Gilbert et al. (2001). Parameter values we use are summarised in Table 1. Justifications for estimates made in this paper are explained in the text. 


\section{The density dependence parameters, $s_{g}, s_{t}$}

The density dependence parameter for grouse, $s_{g}$, is estimated from the model to ensure that when there is no disease grouse reach a carrying capacity of 240 per $\mathrm{km}^{2}$. (Grouse counts of this magnitude have been recorded by Gilbert, unpublished data; Laurenson et al. (2007); GWCT red grouse counts, GWCT (viewed 24/2/2010))

We estimated the density of ticks on heather moorland by combining information on the number of nymphs counted during field surveys with the efficiency of the survey method, then extrapolating up to a $\mathrm{km}$ sq. The survey method used 10m long blanket drags (Gray and Lohan, 1982). We found 1.26 \pm 0.20 (mean \pm s.e.) nymphs per blanket drag, with a maximum of 50, over 9 areas representative of a typical grouse moor. We then tested blanket drag efficiency by adding a known number of nymphs to four 1x $1 \mathrm{~m}$ patches of heather moorland known to not contain ticks previously, and subsequently repeatedly dragging and counting the nymphs collected. The proportion of ticks collected was approximately $1.3 \% \pm 0.3$ (mean \pm s.e.). From this we can estimate a very approximate $9.7 \pm 1.1$ million (mean \pm s.e.) nymphs per km sq, with maximum 385 million. Therefore the tick density dependence, $s_{t}$, is estimated to ensure that ticks are able to reach a carrying capacity in the tens of millions in the absence of sheep tick mops. Actual tick density predictions from the model vary with host availability.

\section{The Ingestion Parameter, $\beta_{3}$}

Gilbert et al. (2004) suggested that 73-98\% of infections of grouse in their first season may stem from the grouse ingesting the ticks. If we take the midpoint, 84\%, then a grouse is 5.25 times more likely to get infected through ingestion than by being bitten during its first season. The first season is from early June when chicks hatch, to August/September when they are shot and questing nymphs begin to decline and is taken as 90 days. The first season lasts for only $\frac{90}{365}$ of the year, and the chance of infection from ingesting an infected tick is 0.109 (Gilbert et al., 2004). Therefore, our estimate for the ingestion parameter, the rate at which ticks are ingested by grouse, now becomes $\beta_{3}=12 \beta_{1}$ (i.e. $5.25 \times \frac{90}{365} \div 0.109$ ), where $\beta_{1}$ is the rate at which a tick bites and infects a grouse.

\section{The Sheep Parameters, $\beta_{6}, \beta_{7}$}

As described in Gilbert et al. (2001) the transmission parameters $\left(\beta_{i}\right)$ are calculated based on the ratio of ticks on grouse and the relevant mammalian host on the same estate. We do not have our own recent data of tick burdens on untreated sheep and grouse at the same site but as the two sites in Gilbert et al. (2001) found 9 and 9.3 nymphs per grouse we are relating our estimates of ticks on sheep to 9 nymphs per grouse to form a crude yet biologically realistic estimate.

We found that the number of ticks attached to untreated sheep varies considerably. Our sample, collected from from 11 untreated sheep on 1 farm on a grouse moor in Scotland, ranged from 0 to 11, with a mean of $4.27 \pm 1.25$ (mean \pm s.e.). In addition the box plots of tick counts on the head and ears of sheep in Ogden et al. (2002) show great variability and in Laurenson et al. (2000) the number of adult female ticks found on lambs varies hugely, from a mean of $0.04 \pm 0.04$ (mean \pm s.e.) on one farm compared to a mean of $24 \pm 1.6$ (mean \pm s.e.) on another. This makes estimating the tick biting rate on sheep difficult.

We ran the model with different values of $\beta_{6}$ and $\beta_{7}$ to assess the effect this has on tick and grouse densities. We found that varying the tick biting rate on sheep within the range we found empirically has very little effect on model output. Consequently we chose to work with $\beta_{6}+\beta_{7}=0.75 \beta_{1}$. That is assuming the total tick burden on sheep is $75 \%$ of the grouse nymph burden. The tick burden on sheep covers both adult and juvenile ticks. Our data showed that approximately $80 \%$ of ticks on sheep are adults so that $\beta_{6}=0.8 \times 0.75 \beta_{1}=0.6 \beta_{1}$ and $\beta_{7}=0.2 \times 0.75 \beta_{1}=0.15 \beta_{1}$.

Laurenson et al. (2003) gives an estimate of the tick burden on sheep and grouse at the same site. This would give estimates of $3.43 \beta_{1}$ and $43.48 \beta_{1}$ for $\beta_{6}$ and $\beta_{7}$ respectively. However, the paper explains that only the adult ticks were counted on sheep and the immature tick burdens were estimated using the ratio 1:5:8 for adults:nymphs:larvae derived from Ogden et al. (1998). Our own data finds a very different ratio of adults to nymphs and larvae on sheep. Consequently we feel it is more thorough to consider the results of the model using both empirical data sets, i.e those estimated in Laurenson et al. (2003) giving a high 


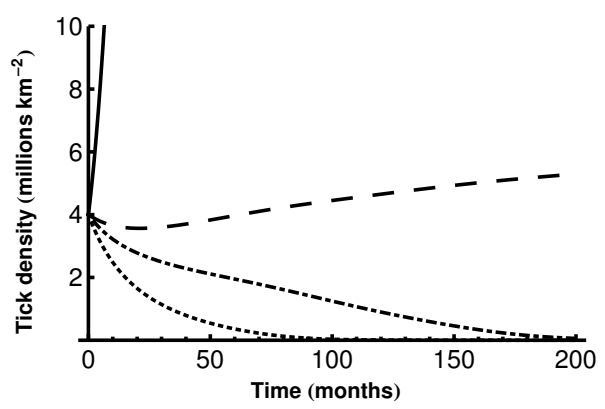

(a) Predicted tick densities

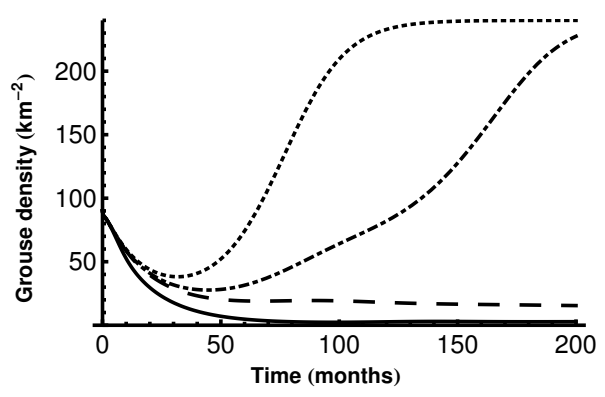

(c) Predicted grouse densities

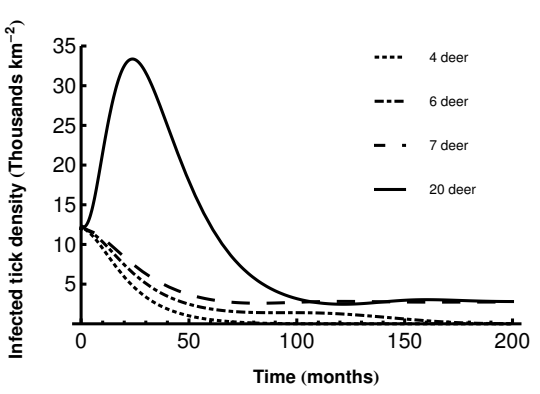

(b) Predicted infected tick densities

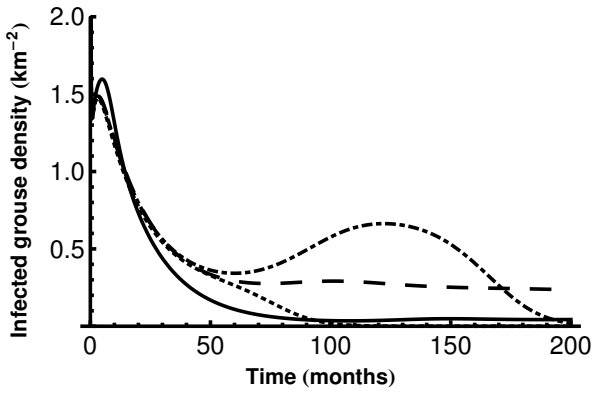

(d) Predicted infected grouse densities

Figure 3: The effect of different deer densities on the effectiveness of sheep tick mops on a)tick, b)infected tick, c)grouse and d)infected grouse densities using the low sheep tick burden model. There are 50 sheep per $\mathrm{km}^{2}$ treated with acaricide of $100 \%$ efficacy. The dotted line represents 4 deer per $\mathrm{km}^{2}$. The dot-dashed line represents 6 deer per $\mathrm{km}^{2}$. The dashed line represents 7 deer per $\mathrm{km}^{2}$. The solid line represents 20 deer per $\mathrm{km}^{2}$. 


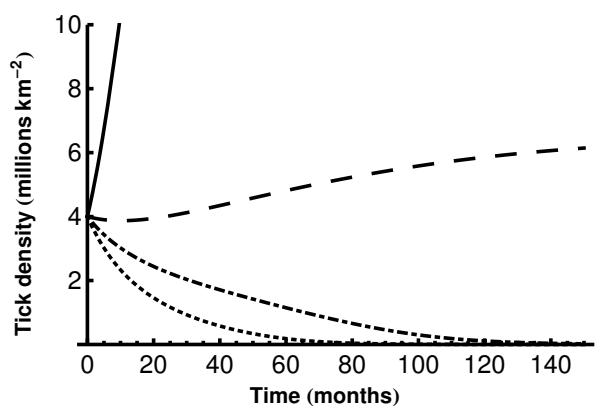

(a) Predicted tick densities

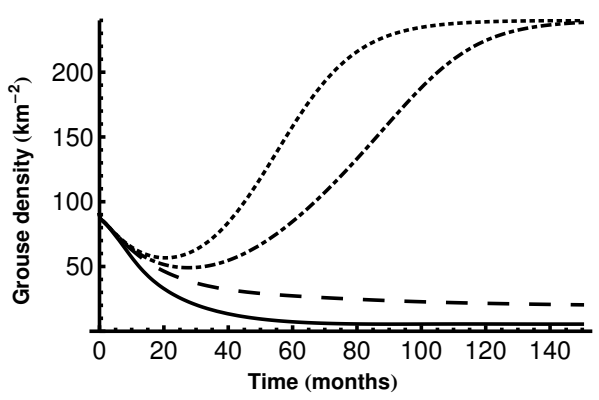

(c) Predicted grouse densities

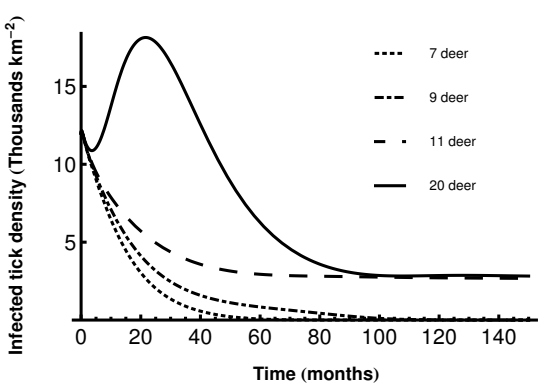

(b) Predicted infected tick densities

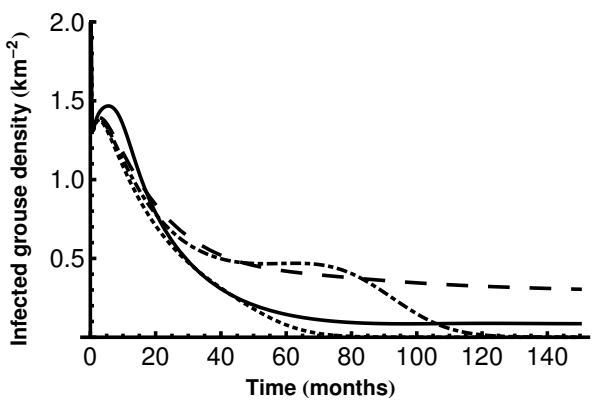

(d) Predicted infected grouse densities

Figure 4: The effect of different deer densities on the effectiveness of sheep tick mops on a)tick, b)infected tick, c)grouse and d)infected grouse densities using the high sheep tick burden model. There are 50 sheep per $\mathrm{km}^{2}$ treated with acaricide of $100 \%$ efficacy. The dotted line represents 7 deer per $\mathrm{km}^{2}$. The dot-dashed line represents 9 deer per $\mathrm{km}^{2}$. The dashed line represents 11 deer per $\mathrm{km}^{2}$. The solid line represents 20 deer per $\mathrm{km}^{2}$.

relative sheep tick burden (approx. 47 times the grouse nymph burden) and our own sheep tick counts giving a low relative sheep tick burden (approx. 0.75 times the grouse nymph burden). The two parameter sets will be referred to as high sheep tick burden and low sheep tick burden respectively.

Please see the appendix for a sensitivity analysis of the parameter estimates.

\section{Results}

The model was simulated over the following scenarios to predict the effect treated sheep would have on grouse and tick densities and LIV prevalence in grouse. In all cases the model was run both with a high sheep tick burden and a low sheep tick burden. 1) 50 treated sheep were added to a grouse moor with no alternative hosts, compared to no sheep. 2) 50 treated sheep were added to grouse moors with varying deer densities. 3) The treated sheep flock size was varied for a given deer density. 4) The acaricide level was varied for a given sheep flock size and deer density.

\subsection{How does the addition of a treated sheep flock affect ticks, LIV and grouse compared to grouse moors with no sheep at all?}

If we consider a scenario of grouse and ticks only then the tick population will die out through lack of hosts for reproduction, since grouse feed only immature ticks. Although a grouse and tick only environment is not biologically realistic it is interesting to consider mathematically the effect of adding treated sheep. If we add to the model a flock of 50 treated sheep (as in GWCT experiments) treated with acaricide of $100 \%$ efficacy per $\mathrm{km}^{2}$ we would expect the decline of the tick population to speed up. Fig. 2a shows that the addition of treated sheep with a low tick burden (dashed line) has virtually no effect on the speed at which 


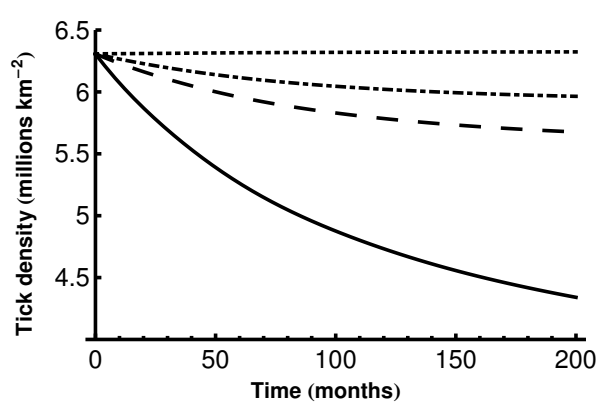

(a) Predicted tick densities

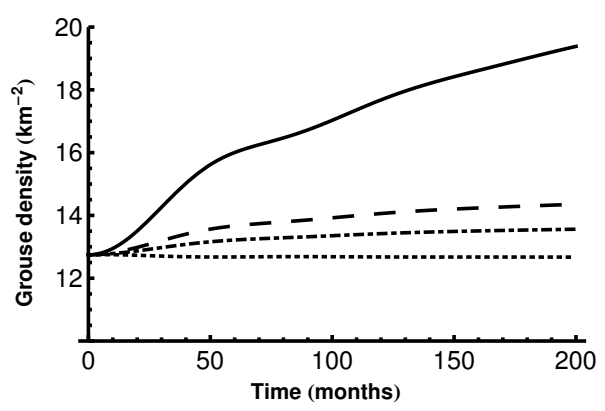

(c) Predicted grouse densities

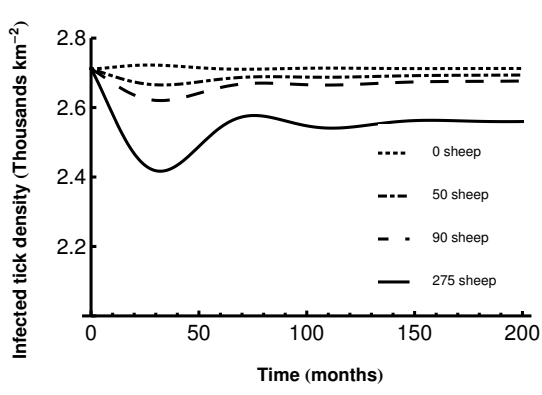

(b) Predicted infected tick densities

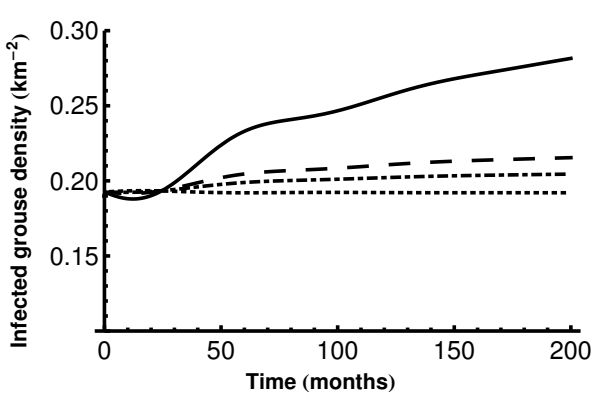

(d) Predicted infected grouse densities

Figure 5: The predicted effect of different sheep flock sizes treated with $100 \%$ efficacious acaricide on an area with 7 deer per $\mathrm{km}^{2}$ on on a)tick, b)infected tick, c)grouse and d)infected grouse densities using the low sheep tick burden model. The dotted line represents no sheep. The dotdashed line represents 50 sheep. The dashed line represents 90 sheep. The solid line represents 275 sheep.

the tick population declines or grouse reach carrying capacity (Fig. 2c) when compared to no sheep (dotted line), indeed the lines are almost indistinguishable.

However, when 50 treated sheep per $\mathrm{km}^{2}$ with a high tick burden are added to the model (solid line) the impact is much greater. The speed with which the grouse reach equilibrium is considerably quicker than with the low sheep tick burden model (Fig. 2c). The tick population reduces by $99 \%$ approximately 14 months faster than with low sheep tick burden model (Fig. 2a).

\subsection{How do alternative hosts, such as deer, impact on the effectiveness of treated sheep?}

Deer amplify the tick population due to their ability to host a large number of ticks (Gray, 1998). Therefore we used the model to predict the effect of different deer densities on the effectiveness of sheep tick mops at reducing ticks and LIV. There is the potential for large numbers of deer to render the use of sheep tick mops ineffective. The sheep flock size was kept at 50 per $\mathrm{km}^{2}$ as in the trials conducted by the GWCT and the effect this would have on areas with different deer densities was explored.

Fig. 3 shows that when there are 6 deer per $\mathrm{km}^{2}$ (dot-dashed line) or fewer then the low sheep tick burden model predicts that the tick numbers are reduced and the grouse reach their carrying capacity at a slower rate than if there were no deer. If there are 7 deer per $\mathrm{km}^{2}$ (dashed line) then the predicted tick population is much higher and causes enough LIV infection for the grouse density to drop dramatically, but not to die out. It is interesting to note that this shows a dramatic effect on the grouse population for a small change in deer density. Although we cannot predict the quantitative effect with any certainty we can be confident that this rapid change will occur for some deer density as the tick population predictions are very sensitive to reproduction host density. For high deer densities ( 9 per $\mathrm{km}^{2}$ or above) the model predicts that the tick population is sufficiently large to cause enough infection for the grouse population to be significantly reduced. 


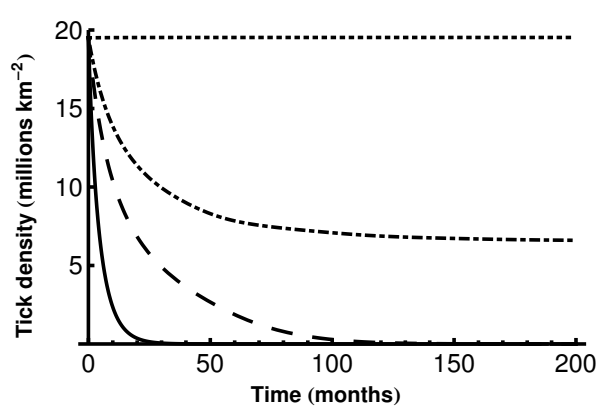

(a) Predicted tick densities

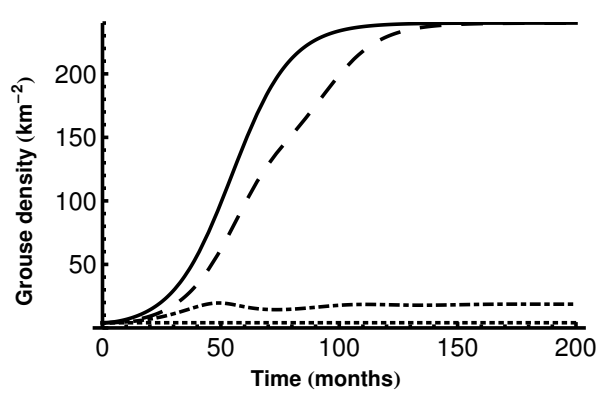

(c) Predicted grouse densities

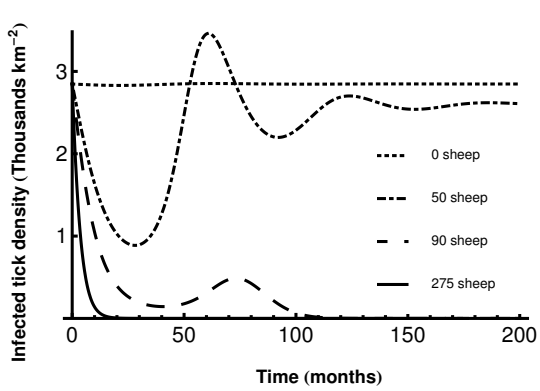

(b) Predicted infected tick densities

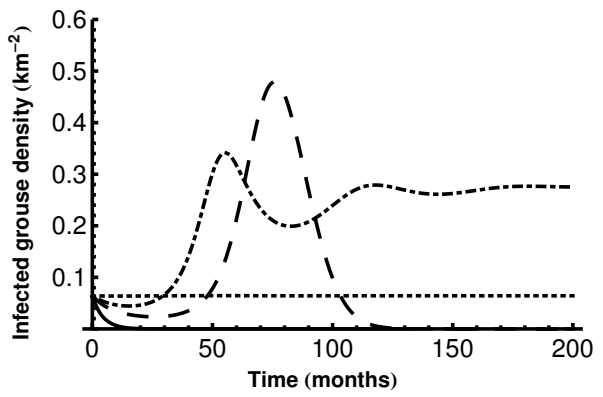

(d) Predicted infected grouse densities

Figure 6: The predicted effect of different sheep flock sizes treated with $100 \%$ efficacious acaricide on an area with 11 deer per $\mathrm{km}^{2}$ on a)tick, b)infected tick, c)grouse and d)infected grouse densities using the high sheep tick burden model. The dotted line represents no sheep. The dotdashed line represents 50 sheep. The dashed line represents 90 sheep. The solid line represents 275 sheep.

This supports the preliminary key findings of the GWCT, who found that for areas of low deer density $\left(<5\right.$ per $\left.\mathrm{km}^{2}\right)$ sheep tick mops may reduce tick burdens on grouse chicks. However, in those areas of high deer densities $\left(>10\right.$ per $\mathrm{km}^{2}$ ) the sheep tick mops were not successful in reducing the tick burden on grouse chicks. (For their full report see Smith (viewed 10/12/2009))

Using the high sheep tick burden model shows a similar pattern of behaviour but this occurs at different deer densities (Fig. 4). The high sheep tick burden model parameter estimates are based on sheep carrying a higher relative tick burden and so one would expect them to be more effective at reducing the tick population. Although the speed of recovery slows as the deer density increases the treated sheep are now predicted by the model to be effective in an area with up to 9 deer per $\mathrm{km}^{2}$ (dot-dashed line Fig. 4). With 10 deer per $\mathrm{km}^{2}$ the model predicts an eventual recovery of the grouse population but taking many years. Above 10 deer per $\mathrm{km}^{2}$ the grouse population declines.

\subsection{What is the impact of different flock sizes on the effectiveness of treated sheep?}

Increasing the number of treated sheep increases the number of deer the system can tolerate before the disease reduces the grouse population. The extent to which this occurs very much depends on the sheep tick burden. It can be seen from Fig. 1a (the low sheep tick burden model) that when there are 50 treated sheep per $\mathrm{km}^{2}$ and $<6.5$ deer per $\mathrm{km}^{2}$ the pathogen is predicted to die out, but the pathogen is predicted to survive when there are more than 6.5 deer per $\mathrm{km}^{2}$. This agrees with the times series plots (Fig. 3) of the model predictions which show grouse reaching carrying capacity for 6 deer per $\mathrm{km}^{2}$ but not for deer densities higher than this. Below 6 deer per $\mathrm{km}^{2}$ the pathogen will always die out irrespective of sheep numbers. The estimated line for the disease persistence threshold is almost vertical for the low sheep tick burden model, indicating that the addition of up to 300 treated sheep has little effect on how many deer the system can tolerate before the disease persists. However, Fig. 5 shows that the predicted tick population is reduced by the addition of increasing numbers of $100 \%$ efficacious treated sheep. This reduction of tick 


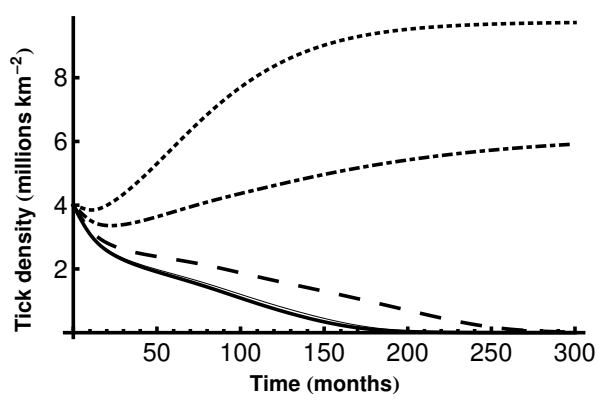

(a) Predicted tick densities

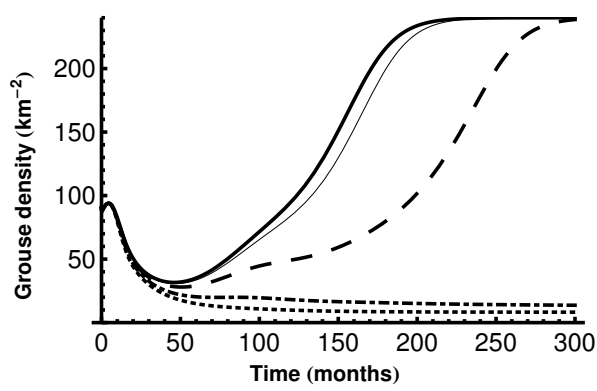

(c) Predicted grouse densities

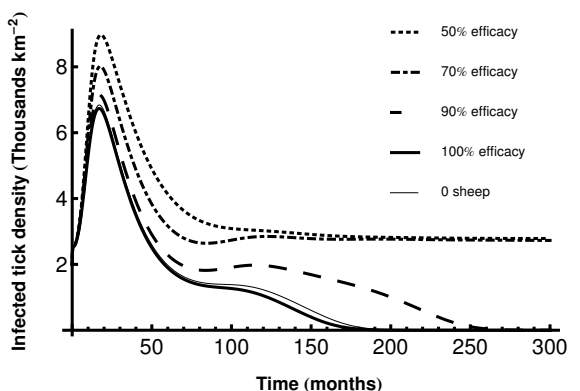

(b) Predicted infected tick densities

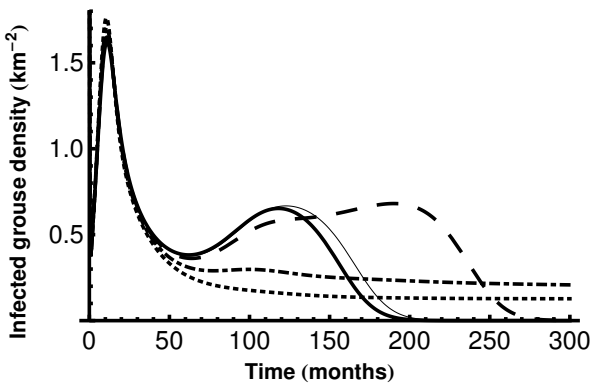

(d) Predicted infected grouse densities

Figure 7: The effect of acaricide efficacy in an environment with 6 deer and 50 treated sheep with low sheep tick burden model on a)tick, b)infected tick, c)grouse and d)infected grouse densities. The dotted line represents $50 \%$ efficacy. The dotdashed line represents $70 \%$ efficacy. The dashed line represents $90 \%$ efficacy. The thick solid line represents $100 \%$ efficacy. The thin solid line represents no sheep.

numbers reduces the opportunity for grouse to become infected and consequently the grouse population is less affected. Therefore, although the pathogen can persist the grouse population suffers lower mortality rates with treated sheep than without treated sheep. This is illustrated in Fig. 5 when there are 7 deer per $\mathrm{km}^{2}$ the predicted tick population is reduced from 5.7 million per $\mathrm{km}^{2}$ to 5.3 million per $\mathrm{km}^{2}$ when 50 treated sheep per $\mathrm{km}^{2}$ are included in the low sheep tick burden model. In this case the model predicts that the virus will persist in the grouse population, but the use of treated sheep allows additional grouse to survive. The predicted density of grouse per $\mathrm{km}^{2}$ increases as the number of treated sheep increases in the model. Without treated sheep the grouse reach a predicted equilibrium of 14.2 grouse per $\mathrm{km}^{2}$, but with 50 treated sheep per $\mathrm{km}^{2}$ the grouse reach an equilibrium of 15.5 per $\mathrm{km}^{2}$ this increases to 16.6 per $\mathrm{km}^{2}$ with 90 sheep per $\mathrm{km}^{2}$. The use of sheep tick mops also shortens the length of time the virus persists in the grouse population when there are 6 deer per $\mathrm{km}^{2}$ (Fig. 3) and allows the grouse to recover to their carrying capacity at a faster rate.

The effect of increasing the flock size of treated sheep is more dramatic with the high sheep tick burden model, as one would expect. Fig. 1b predicts that for the high sheep tick burden model increasing the sheep density to 275 per $\mathrm{km}^{2}$ (commercial stocking densities) allows over 25 deer per $\mathrm{km}^{2}$ before LIV persists. It is unlikely that sheep would be stocked at such high density on grouse moors due to poor grazing habitat. A more realistic hill stocking density is around 90 sheep per $\mathrm{km}^{2}$, which allows 12 deer per $\mathrm{km}^{2}$ before disease persistence. Considering now the scenario of 11 deer per $\mathrm{km}^{2}$, Fig 6 a illustrates that a flock of 50 treated sheep per $\mathrm{km}^{2}$ added to the high sheep tick burden model dramatically reduces the predicted tick population to 6.4 million per $\mathrm{km}^{2}$ from 19.5 million per $\mathrm{km}^{2}$ with no sheep. This allows the grouse to reach a higher predicted equilibrium of 19.5 per $\mathrm{km}^{2}$ as opposed to 4.1 per $\mathrm{km}^{2}$ without sheep. This highlights again that although the virus is still persisting in the grouse population the use of sheep tick mops is predicted to allow a greater number of grouse. 


\subsection{How does the efficacy of the acaricide impact on the effectiveness of treated sheep?}

In practice it is very difficult to ensure that the acaricide applications are fully effective at preventing all ticks from attaching to all sheep. Even if initial applications are $100 \%$ efficacious the efficacy decreases over time. Therefore we used the model to predict the effect different levels of efficacy have on the tick and grouse population densities.

If a flock of 50 sheep per $\mathrm{km}^{2}$ treated with $100 \%$ efficacious acaricide is added to the model with the low sheep tick burden model and 6 deer per $\mathrm{km}^{2}$ then the ticks will die out and the grouse population will recover. If the acaricide efficacy is $90 \%$ then the speed of the recovery of the grouse is much slower. However Fig. 7 shows that if the acaricide is only $50 \%$ or $70 \%$ efficacious then the tick numbers increase and the grouse numbers are reduced. If the model is run with no sheep and 6 deer per $\mathrm{km}^{2}$ then it is predicted that the grouse will recover as there is not a sufficient deer density to sustain the tick population. Consequently, if the efficacy cannot be maintained at a high level then no sheep at all will give a higher grouse yield than a flock of less effective sheep. This may seem counterintuitive as some intervention is surely better than none. However, the model predicts this is not the case. Introducing untreated sheep would amplify the tick population as they would be providing hosts for the adult female ticks, who could then reproduce. In contrast, if sheep treated with $100 \%$ efficacious acaricide are introduced then they would kill these ticks. However, if the efficacy is not sufficiently high there is a fine balance between killing enough ticks to impede reproduction and allowing too many to reproduce.

\section{Discussion}

The aim of this paper was to investigate theoretically the effectiveness of controlling a vector-borne disease in one species through the management of a second species to reduce the vector population. We used the LIV system as a particular case to parameterise our model. The model was simulated over the following scenarios with a high sheep tick burden and a low sheep tick burden. 1) 50 treated sheep were added to a grouse moor with no alternative hosts, compared to no sheep. 2) 50 treated sheep were added to grouse moors with varying deer densities. 3) The treated sheep flock size was varied for a given deer density. 4) The acaricide level was varied for a given sheep flock size and deer density. This enabled us to answer the following questions; 1) How does the addition of a treated sheep flock affect ticks, LIV and grouse compared to grouse moors with no sheep at all? 2) How do alternative hosts, such as deer, impact on the effectiveness of treated sheep? 3) What is the impact of different flock sizes on the effectiveness of treated sheep? 4) How does the efficacy of the acaricide impact on the effectiveness of treated sheep?

In general the model predicted that treated sheep could speed up the decline of the tick population on a moor with no alternative tick hosts and could reduce the tick population if the density of alternative tick reproduction hosts was low. Increasing the density of treated sheep for a given deer density is predicted by the model to decrease the tick population. For a given treated sheep flock size and deer density the model predicts that decreasing the acaricide level much below $90 \%$ can actually allow the tick population to increase. The model also predicts that the effect of sheep tick mops very much depends on the sheep tick burden.

The model predicted that using acaricide treated sheep can be an effective method to reduce the tick population on a grouse moor providing there are few deer $\left(<6\right.$ per $\left.\mathrm{km}^{2}\right)$ and efficacy levels of the acaricide are kept high (>90\%). Our work supports, at least qualitatively, experimental work by the GWCT (Smith, viewed 10/12/2009) that also suggests that in the presence of high deer numbers the sheep tick mops will be rendered ineffective. The model predicts that not only are low efficacies less effective, but may in fact be worse than no sheep at all.

An exciting theoretical result which has emerged unexpectedly from this work is that the addition of ingestion means that $R_{0}$ no longer behaves as the threshold for disease persistence. This is a very unusual result and we believe that it is the first time that this has come to light. The formula for $R_{0}$ which can be derived in a number of different ways (ie from the Jacobian as in Norman et al. (2004) or the next generation matrix (Diekmann et al., 1990)) is given in section 2.2. Normally when $R_{0}>1$ the disease can persist and when $R_{0}<1$ the disease cannot persist. However, we have found here that the simulations 
do not agree with this threshold and in fact the disease can persist when $R_{0}<1$. This is because of the feedback mechanism that is created by the ingestion. In a totally susceptible population grouse and ticks are at their carrying capacity, however, with ingestion the carrying capacity of ticks is lower than it would be without ingestion because the grouse are eating the ticks. If we add disease to this system then the grouse population is reduced which causes an increase in the tick population which then causes a greater decrease in the grouse population. Therefore the disease can persist more easily and calculating $R_{0}$ using the formula derived from the definition underestimates the ability of the disease to persist. This is a really interesting result and requires some further investigation to determine if there are other systems for which this is likely to be an important phenomenon and which aspects of the system are essential for it to occur.

We have not investigated the biological interaction between the sheep and deer. In nature it is possible that where sheep are removed from the moor more deer may move in to fill the void created. It may be in this case that even ineffective sheep are better than none if the alternative is an increase in deer density. We do not have any data on the relationship between deer and sheep that shows the effect the presence of sheep has on the density of deer but anecdotal evidence suggests there is a negative interaction between the two species. The segregation of wild and domestic animals has been documented (Loft et al., 1993; Acevedo et al., 2007) with Fankhauser et al. (2008) proposing that dung avoidance may explain why chamois tend to avoid domestic sheep. Due to the high tick burden of deer it is intuitive that only a few deer would be needed to feed the same number of ticks as a full flock of sheep with a low tick burden. Using the parameter values from our low sheep tick burden model we can see that the relationship between deer and sheep burdens is $S=\frac{16}{1-d} D$, where $d$ is the acaricide efficacy. If for example the efficacy levels were only $50 \%$ and we knew that in the absence of sheep there would be 10 deer per $\mathrm{km}^{2}$ then having up to 320 treated sheep per $\mathrm{km}^{2}$ would be preferable to having 10 deer per $\mathrm{km}^{2}$ and having more than 320 treated sheep per $\mathrm{km}^{2}$ would be worse than having 10 deer per $\mathrm{km}^{2}$. However, if we knew there would only be 5 deer per $\mathrm{km}^{2}$ in the absence of sheep then having up to 160 treated sheep per $\mathrm{km}^{2}$ would be preferable to the deer and having more than 160 treated sheep per $\mathrm{km}^{2}$ would be worse than 5 deer per $\mathrm{km}^{2}$.

Our model is very sensitive to deer density, suggesting that deer play a major role in the persistence of the tick population and LIV. Deer can carry high tick burdens, and as a result they can allow the tick population to be maintained. If the deer could be used as tick mops rather than the sheep this may, at least in theory reduce the tick population and LIV prevalence in grouse more effectively. If sheep alone are being used as tick mops but the acaricide is not highly efficacious the sheep may create more blood meals for the adult ticks and may allow ticks to reproduce at a greater rate than they are removed. Where deer are present any treatment to lower the number of ticks deer carry will be beneficial. However, treating deer in practice has many issues; legally, ethically and logistically. Acaricides are not licensed for use on wildlife. There are major difficulties with the application of acaricide to deer in practice and the dose of acaricide cannot be controlled. The percentage of deer receiving the treatment would vary as deer come and go from the treatment site. However, the ' 4 poster' method has been used with some success in the US (Carroll et al., 2002). There is also the problem of withdrawing the product before culling as deer are used for human consumption. The use of acaricide on deer may also increase the incidence of acquired resistance of the ticks to the acaricide.

The model has several other limitations. It is difficult to accurately measure many of the model parameters and some have been estimated from fitting the model to achieve biologically plausible results. The sensitivity analysis indicated that the model outputs were affected most by variation in the tick parameters: tick birth and death rates and tick biting rates on deer and sheep (see Appendix). For accurate quantitative predictions, therefore, it is these parameters that require the most accurate estimated values. The estimates we used for these parameters were derived from the literature and our own data, and there is considerable variation in these values between studies, depending on available hosts, time of year, region. More empirical data are needed on tick burdens of different tick stages on all the different host in the same place at the same time. We emphasise that the model outputs may not be quantitatively accurate in their predictions of grouse densities for particular sheep and deer densities. However, the models reflect the general qualitative patterns for how grouse densities may change with varying sheep and deer densities.

We have few data on the tick burdens of sheep on sites where we can make direct comparisons with other host tick burdens. Our own data includes counts of all tick life stages explicitly, but we do not have tick counts on grouse at the same site to make a direct comparison. Laurenson et al. (2003) does have red 
grouse tick counts but uses estimates for the larvae and nymph counts on sheep using larvae:nymph:adult ratios from Ogden et al. (1998). The ratios given are very different from the ratios we found. Ogore et al. (1999) compared the tick burden on different sheep breeds in Kenya and found that the burdens varied between breeds. It could be that different breeds in the UK display similar differences, which may help account for the differences we found. Different sites may also have different densities of alternative hosts, for example, a site with more small mammals and birds that feed larvae may result in fewer larvae on sheep. The limitations of the available relevant data make it difficult to quantitatively estimate the efficacy of sheep tick mops, although qualitative patterns still hold.

In order to validate our model we would need to be able to compare the burdens of different tick stages on all the hosts (grouse, sheep and deer) at the same site. We would then be able to improve our estimate of the tick burdens within the model and the role each host plays in the tick life cycle. Although as Laurenson et al. (2003) shows the ratios between tick stages on each host type differ from site to site. These differ again from the ratios found in Gilbert et al. (2001) from which many of our parameters are taken. The variability of nature makes it impossible to develop a quantitatively accurate mathematical model for all estates. However, we believe the qualitative results from our two models give useful insights into the dynamics of the LIV system and the use of sheep tick mops. A discussion of the sensitivity analysis is given in the appendix.

We assumed homogenous space but a grouse moor is made up of a patchwork of heather and grass areas and in reality the sheep tend to prefer the grassy areas. Consequently the sheep may be less likely to pick up the ticks questing in the heather which is the habitat the grouse prefer. We do not explicitly model the spatial heterogeneity of the distribution of the tick hosts. However, the estimation of the tick burden for each host takes this in to account and, as a result, the sheep have a lower tick burden than the grouse in the low sheep tick burden model.

Throughout the model the life stages of the tick are combined. The effect of the different life stages in the transmission of the disease have been taken account of in the estimation of the various $\beta_{i}$. Future model improvements could include the stages explicitly as the different tick stages may sometimes have their peak of activity at different times of the year (Randolph et al., 2002). This would make the model much more complicated and we do not at present have the data to make this possible.

Similarly the grouse life stages are combined, but as it is only the chicks which consume the ticks in the first three weeks of life it may be appropriate to model chicks and adults separately. This would allow ticks to be ingested by the chicks for a particular three week period rather than averaging out over the year as at present.

In conclusion, our model supports the idea that controlling the vector population by managing one species can mitigate disease and enhance the population of a second target species. Specifically, our case study suggests that treating sheep with acaricide can, under certain circumstances, reduce the population of I. ricinus, reduce the prevalence of LIV, and increase the red grouse population. This is a more benign approach than other documented attempts at controlling disease in one species by targeting another species, such as culling badgers to control bovine tuberculosis in cattle and bison to control brucellosis in cattle. However, our study highlights the difficulties of multi-host vector-borne systems which, importantly, raises issues with this more benign method. For example, sheep tick mops are predicted to be effective only with very low densities of alternative hosts such as deer, and at very high acaricide efficacies on sheep. Such circumstances may be rarely realised in practice and there may be ethical implications with attempts to achieve them. For example, there may be health and welfare issues for farmers and livestock of increased exposure to high acaricide levels. This study exemplifies how models can be useful in predicting the effectiveness of various control strategies under different scenarios, where empirical studies are not possible. It is important, however, to consider the practical and ethical implications of implementing such methods. Modelling studies can help focus the implementation of control strategies for maximum effect under the most appropriate circumstances.

Despite the limitations of this simple model this approach can be a useful tool for predicting qualitatively the outcomes of various field scenarios. These results could help inform policy of tick and tick borne disease control. Although we focus here on the LIV system we believe that similar methods could be used to model other tick borne disease systems. 


\section{Acknowledgements}

R Porter was funded by a CASE studentship from NERC and the Macaulay Land Use Research Institute. We thank the Game and Wildlife Conservation Trust for access to the sheep farm we used for counting tick burdens on sheep. We thank Edward Jones, Peter Goddard and the anonymous referees for comments on the manuscript.

\section{References}

P Acevedo, J Cassinello, and C Gortazar. The Iberian ibex is under an expansion trend but displaced to suboptimal habitats by the presence of extensive goat livestock in central Spain. Biodiversity And Conservation, 16(12):3361-3376, 2007.

JF Carroll, PC Allen, DE Hill, JM Pound, JA Miller, and JE George. Control of Ixodes scapularis and Amblyomma americanum through use of the '4-poster' treatment device on deer in Maryland. Experimental and Applied Acarology, 28(1):289-296, 2002.

LM Cooksey, DG Haile, and GA Mount. Computer-Simulation Of Rocky-Mountain-Spotted-Fever Transmission By The American Dog Tick (Acari, Ixodidae). Journal Of Medical Entomology, 27(4):671-680, 1990.

O Diekmann, JP Heesterbeek, and JAJ Metz. On the definition and the computation of the basic reproduction ratio $r_{0}$ in models for infectious diseases in heterogeneous populations. Journal of Mathematical Biology, 28(4):365-382, 1990.

CA Donnelly, R Woodroffe, DR Cox, FJ Bourne, CL Cheeseman, RS Clifton-Hadly, G Wei, G Gettinby, P Gilks, H Jenkins, WT Johnston, AM Le Fevre, JP McInerney, and WI Morrison. Positive and negative effects of widespread badger culling on tuberculosis in cattle. Nature, 439:843-846, 2006.

R Fankhauser, C Galeffi, and W Suter. Dung avoidance as a possible mechanism in competition between wild and domestic ungulates: two experiments with chamois Rupicapra rupicapra. European Journal Of Wildlife Research, 54(1):88-94, 2008.

MW Gaunt. The epidemiology of louping ill virus and flavivirus evolution. PhD thesis, University of Oxford, 1997.

L Gilbert, R Norman, MK Laurenson, HW Reid, and PJ Hudson. Disease persistence and apparent competition in a three-host community: an empirical and analytical study of large-scale, wild populations. Journal of Animal Ecology, 70(6):1053-1061, 2001.

L Gilbert, LD Jones, MK Laurenson, EA Gould, HW Reid, and PJ Hudson. Ticks need not bite their red grouse hosts to infect them with louping ill virus. In The Royal Society of London Series B-Biological Sciences, volume 271, pages S202-S205, 2004.

JS Gray. The ecology of ticks transmitting lyme borreliosis. Experimetal and Applied Acarology, 22: 249-258, 1998.

JS Gray and G Lohan. The development of a sampling method for the tick ixodes ricinus and its use in a redwater fever area. Annuls of Applied Biology, 101:421-427, 1982.

GWCT. Red grouse counts in 2008. http://www.gwct.org.uk/research__surveys/species_research/birds/red_grouse_bap_species/1519.asp, viewed 24/2/2010.

NA Hartemink, SE Randolph, SA Davis, and JAP Heesterbeek. The basic reproduction number for complex disease systems: Defining R-0 for tick-borne infections. American Naturalist, 171(6):743-754, 2008.

LD Jones, M Gaunt, RS Hails, K Laurenson, PJ Hudson, H Reid, P Henbest, and EA Gould. Transmission of louping ill virus between infected and uninfected ticks co-feeding on mountain hares. Medical and Veterinary Entomology, 11(2):172-176, 1997. 
AD Kirby, AA Smith, TG Benton, and PJ Hudson. Rising burden of immature sheep ticks (ixodes ricinus) on red grouse (lagopus lagopus scoticus) chicks in the scottish uplands. Medical and Veterinary Entomology, 18(1):67-70, 2004.

M. K. Laurenson, I. J. McKendrick, H. W. Reid, R. Challenor, and G. K. Mathewson. Prevalence, spatial distribution and the effect of control measures on louping-ill virus in the forest of bowland, lancashire. Epidemiology And Infection, 135(6):963-973, 2007.

MK Laurenson, PJ Hudson, K McGuire, SJ Thirgood, and HW Reid. Efficacy of acaricidal tags and pouron as prophylaxis against ticks and louping-ill in red grouse. Medical and Veterinary Entomology, 11: 389-393, 1997.

MK Laurenson, R Norman, HW Reid, I Pow, D Newborn, and PJ Hudson. The role of lambs in louping-ill virus amplification. Parasitology, 120(Part 2):97-104, 2000.

MK Laurenson, RA Norman, L Gilbert, HW Reid, and PJ Hudson. Identifying disease reservoirs in complex systems: mountain hares as reservoirs of ticks and louping-ill virus, pathogens of red grouse. Journal Of Animal Ecology, 72(1):177-185, 2003.

ER Loft, JG Kie, and JW Menke. Grazing In The Sierra-Nevada - Home-Range And Space Use Patterns Of Mule Deer As Influenced By Cattle. California Fish And Game, 79(4):145-166, 1993.

F Mougeot, M Moseley, F Leckie, J Martinez-Padilla, A Miller, N Pounds, and JR Irvine. Reducing tick burdens on chicks by treating breeding female grouse with permethrin. Journal Of Wildlife Management, 72(2):468-472, 2008.

R. Norman, D Ross, MK Laurenson, and PJ Hudson. The role of non-viraemic transmission on the persistence and dynamics of a tick borne virus - louping ill in red grouse (lagopus lagopus scoticus) and mountain hares (lepus timidus). Journal of Mathematical Biology, 48(2):119-134, 2004.

CJ O'Callaghan, GF Medley, TF Peter, and BD Perry. Investigating the epidemiology of heartwater (Cowdria ruminantium infection) by means of a transmission dynamics model. Parasitology, 117(Part 1): 49-61, 1998.

NH Ogden, RS Hailes, and PA Nuttall. Interstadial variation in the attachment sites of Ixodes ricinus ticks on sheep. Experimental and Applied Acarology, 22(4):227-232, 1998.

NH Ogden, ANJ Casey, NP French, KJ Bown, JDW Adams, and Z Woldehiwet. Natural Ehrlichia phagocytophila transmission coefficients from sheep 'carriers' to Ixodes ricinus ticks vary with the numbers of feeding ticks. Parasitology, 124(Part 2):127-136, 2002.

PB Ogore, RL Baker, M Kenyanjui, and W Thorpe. Assessment of natural Ixodid tick infestations in sheep. Small Ruminant Research, 33(2):103-107, 1999.

ME Pietzsch, JM Medlock, L Jones, D Avenell, J Abbott, P Harding, and S Leach. Distribution of ixodes ricinus in the british isles: investigation of historical records. Medical And Veterinary Entomology, 19 (3):306-314, 2005.

SE Randolph, RM Green, AN Hoodless, and MF Peacey. An empirical quantitative framework for the seasonal population dynamics of the tick Ixodes Ricinus. International Journal for Parasitology, 32: 979-989, 2002.

HW Reid. Experimental Infection of Red Grouse with Louping-Ill Virus (Flavivirus Group) .1. Viremia and Antibody-Response. Journal of Comparative Pathology, 85(2):223-229, 1975.

R Rosa and A Pugliese. Effects of tick population dynamics and host densities on the persistence of tickborne infections. Mathematical Biosciences, 208(1):216-240, 2007.

JPW Scharlemann, PJ Johnson, AA Smith, DW Macdonald, and SE Randolph. Trends in ixodid tick abundance and distribution in great britain. Medical And Veterinary Entomology, 22(3):238-247, 2008. 
A Smith. Are sheep tick-mops effective in scotland? http://www.gwct.org.uk/research__surveys/species_research/birds/red_grouse_bap_species/279.asp, viewed 10/12/2009.

USDA-APHIS. United states department of agriculture - animal and plant health inspection service, washington d.c. http://www.aphis.usda.gov/animal_health/animal_diseases

/brucellosis/, 2009.

EJ Watts, SCF Palmer, AS Bowman, RJ Irvine, A. Smith, and J. M. J. Travis. The effect of host movement on viral transmission dynamics in a vector-borne disease system. Parasitology, 136(10):1221-1234, 2009.

R Woodroffe, CA Donnelly, DR Cox, FJ Bourne, CL Cheeseman, RJ Delahay, G Gettinby, and WI McInerney, JP abd Morrison. Effects of culling badger Meles meles spatial organization: implcations for the control of bovine tuberculosis. Journal of Applied Ecology, 43:1-10, 2006.

\section{A Sensitivity Analysis}

Sensitivity analysis was conducted following the methods of Watts et al. (2009). The analysis was done for both the high and low sheep tick burden models at different deer densities, with and without sheep. Each of these models was run 500 times selecting parameters randomly from a range $\pm 1 \%$ of the parameter used throughout the paper. The outputs from these simulations were then correlated against the individual parameters and interactions between parameters within the groups concerning grouse dynamics, tick dynamics and viral dynamics respectively. The results from this analysis are given in Table 2 .

The relative effect on the model outputs of changing each parameter individually by $\pm 10 \%$ was also investigated. The percentage change on the model output is given in Table 3 whenever the percentage change is greater than $10 \%$. The deer density for each model was chosen to allow the grouse to reach an intermediate density with the parameters used throughout the paper.

Correlation Effects In general the grouse dynamic parameters (birth and death rates) and corresponding interactions show high correlation with the predicted grouse density only for low deer density. This is the same for both models and can be explained by the lack of ticks at this deer density. At low deer densities the tick population cannot be maintained at a high enough density to allow LIV to persist so the disease dynamics are not important. As a consequence the grouse population dynamics are governed by the natural birth and death rates.

The grouse dynamics parameters show high correlation with the virus prevalence for high deer densities. At high deer densities the tick population is large enough to allow disease persistence and the grouse population is regulated by the disease. If the natural death rate is increased this will reduce the grouse population already at a low density, which reduces the proportion of infected grouse.

The tick dynamic parameters do not show a high correlation with any of the model outputs.

Of the viral dynamics $\beta_{3}$, the rate at which grouse ingest ticks, has the highest correlation both with the grouse density and virus prevalence at higher deer densities. At the intermediate deer density the ingestion of ticks shows a positive effect on the grouse population. This seems counterintuitive as ingestion is another route of infection but here the tick population is small enough for the grouse to be able to consume a sufficient quantity that the overall effect is to reduce the tick population and thus the virus prevalence. However, at higher deer densities the tick population is large and the ingestion of ticks has a limited effect on the tick population and the overall effect on the grouse population is negative; now ingestion is essentially just another route of infection.

$\beta_{7}$, the rate at which immature ticks attach to sheep, also shows a positive correlation with the grouse population for higher deer densities. At low deer densities the tick population is already small. At higher deer densities the increased attachment, and subsequent death, of ticks that attach to sheep would be expected to have a positive effect on the grouse population as the tick population is reduced and with it the virus prevalence. 
Individual Parameters The parameters that have the largest disproportionate effect on the model outputs are the same for both the high and low sheep tick burden models. Where there are differences the effect is only just beyond what would be expected and may be simply due to the effect of the particular deer density. Section 3.2 discusses the impact of different deer densities on the model predictions.

The tick parameters show a highly disproportionate effect on the model predictions for the grouse density. In particular decreasing $a_{t}$ the tick birth rate, increasing $b_{t}$ the death rate and decreasing $\beta_{5}$ the tick biting rate on deer which will all reduce the tick population have a huge positive effect on the predicted grouse population. Although a positive effect would be expected as a reduction in the tick population will reduce the virus prevalence the magnitude of the effect is an order of magnitude higher than expected. This can be explained by the sheer size of the tick population and a small relative change can be a large change in terms of actual numbers. We are at a point where a small change in the tick population has a large effect on the grouse population and so the effect is disproportionate. Consequently the model is sensitive to the estimates of these parameters.

Although a change to those parameters increasing the tick population does have a negative effect on the grouse population predictions the magnitude is not as extreme.

In the high sheep tick burden model a change to $\beta_{7}$ the rate at which immature ticks attach to sheep has a disproportionate effect on the grouse population predictions. The explanation for this may be due to the effect this parameter in the high sheep tick burden model has on the tick population and small relative changes now make sufficiently large numerical changes to show a large effect on the grouse population.

A smaller, but still disproportionate, effect can be seen by changing $a_{g}$ the grouse birth rate, $b_{g}$ the natural grouse death rate and $\beta_{2}$ the rate at which infected ticks bite grouse.

Interestingly although $\beta_{3}$ the rate at which ticks are ingested by grouse showed high correlation for both models it does not have a disproportionate effect on model outputs. 


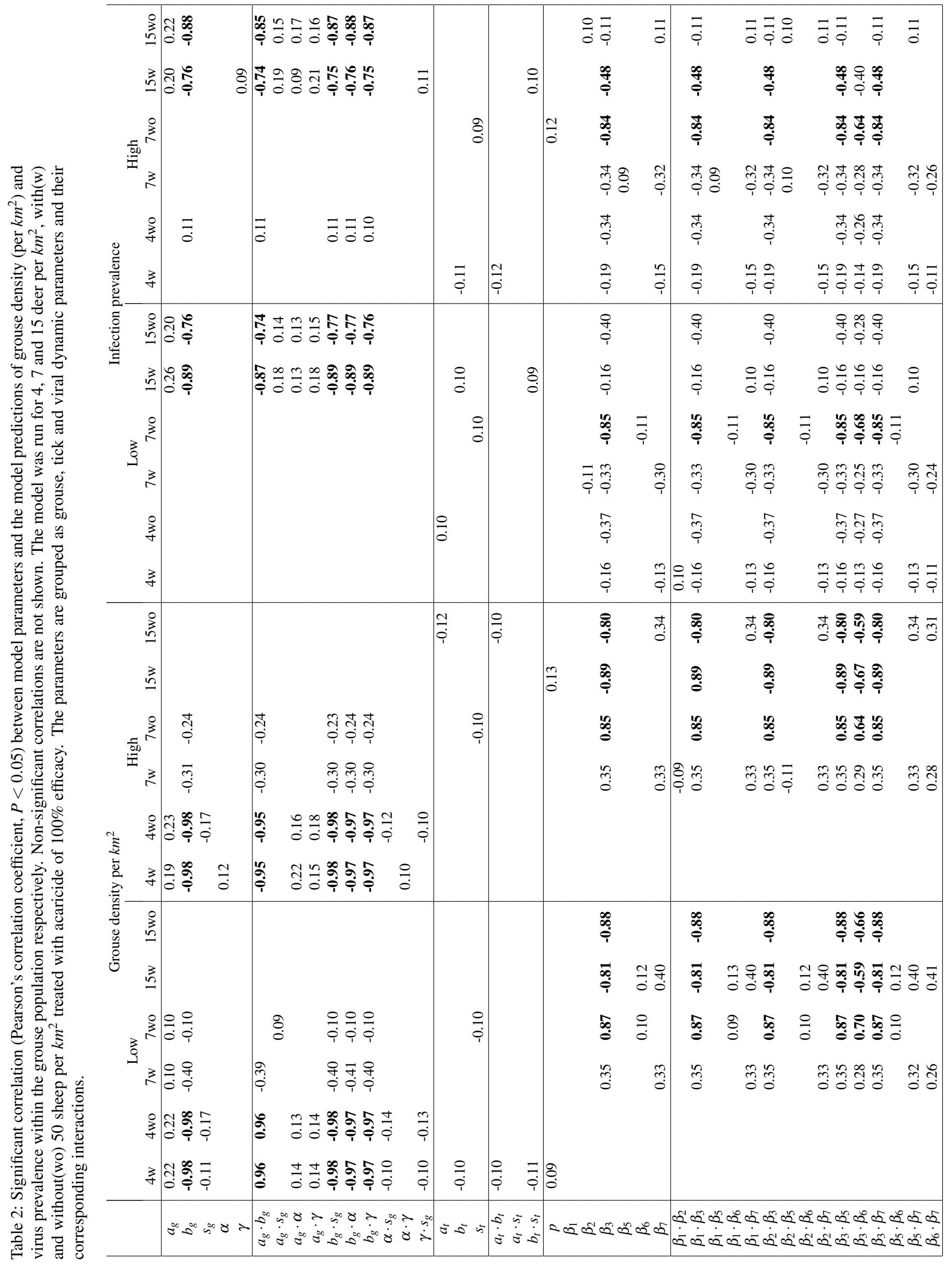


Table 3: The percentage change (not shown if $<10 \%$ ) of the model predictions of total grouse density and infection prevalence in the grouse population after changing each parameter individually by $\pm 10 \%$. The results are given for both the high and low sheep tick burden models run with 11 and 7 deer per $\mathrm{km}^{2}$ respectively.

\begin{tabular}{|c|c|c|c|c|}
\hline & \multicolumn{2}{|c|}{ Grouse density per $\mathrm{km}^{2}$} & \multicolumn{2}{|c|}{ Infection prevalence } \\
\hline & Low & High & Low & High \\
\hline$a_{g}+$ & 13 & \multirow[t]{3}{*}{11} & 21 & 22 \\
\hline$a_{g^{-}}$ & -12 & & -21 & -22 \\
\hline$b_{g}+$ & -11 & & -12 & -11 \\
\hline$b_{g^{-}}$ & 16 & \multirow[t]{7}{*}{12} & 11 & 11 \\
\hline$s_{g}+$ & & & \multirow{6}{*}{12} & \multirow{6}{*}{12} \\
\hline$s_{g^{-}}$ & & & & \\
\hline$\alpha+$ & & & & \\
\hline$\alpha-$ & & & & \\
\hline$\gamma+$ & & & & \\
\hline$\gamma-$ & & & & \\
\hline$a_{t}+$ & -51 & -45 & \multirow{8}{*}{$\begin{array}{l}-37 \\
-31\end{array}$} & \multirow{8}{*}{$\begin{array}{l}-71 \\
-13\end{array}$} \\
\hline$a_{t^{-}}$ & 297 & 553 & & \\
\hline$b_{t}+$ & 248 & 113 & & \\
\hline$b_{t^{-}}$ & -51 & -35 & & \\
\hline$s_{t}+$ & & 12 & & \\
\hline$s_{t^{-}}$ & \multirow{3}{*}{\multicolumn{2}{|c|}{-11}} & & \\
\hline$p+$ & & & & \\
\hline$p-$ & & & & \\
\hline$\beta_{1}+$ & \multirow{5}{*}{$\begin{array}{c}-12 \\
17\end{array}$} & & \multirow{10}{*}{-32} & \multirow{10}{*}{-56} \\
\hline $\begin{array}{l}\rho_{1^{-}} \\
\beta_{2+}+\end{array}$ & & & & \\
\hline$\beta_{2^{-}}$ & & 15 & & \\
\hline$\beta_{3}+$ & & & & \\
\hline$\beta_{3^{-}}$ & & & & \\
\hline$\beta_{5}+$ & -45 & -39 & & \\
\hline$\beta_{5^{-}}$ & 247 & 424 & & \\
\hline $\begin{array}{l}\beta_{6}+ \\
\beta_{6-}\end{array}$ & & & & \\
\hline$\beta_{7}+$ & & 39 & & \\
\hline$\beta_{7^{-}}$ & & -22 & & \\
\hline
\end{tabular}

